TITLE:

\title{
Effect of alloying elements on irradiation hardening behavior and microstructure evolution in $\mathrm{BCC} F e$
}

$\operatorname{AUTHOR}(S)$ :

Yabuuchi, Kiyohiro; Kasada, Ryuta; Kimura, Akihiko

\section{CITATION:}

Yabuuchi, Kiyohiro ...[et al]. Effect of alloying elements on irradiation hardening behavior and microstructure evolution in BCC Fe. Journal of Nuclear Materials 2013, 442(1-3,

Supplement 1): S790-S795

ISSUE DATE:

2013-11

URL:

http://hdl.handle.net/2433/179320

\section{RIGHT:}

(C) 2013 Elsevier B.V.; This is not the published version. Please cite only the published version.; この論文は出版社版でありません。引用の際に は出版社版をご確認ご利用ください。 


\section{Title}

Effect of alloying elements on irradiation hardening behavior and microstructure evolution in BCC Fe.

\section{Authors}

Kiyohiro Yabuuchia, Ryuta Kasada a , Akihiko Kimura ${ }^{a}$

Affiliation

a Institute of Advanced Energy, Kyoto University, Uji, Kyoto, Japan

\section{Corresponding Author}

Name: Kiyohiro Yabuuchi

Postal address: Gokasho, Uji, Kyoto 611-0011, Japan

Telephone number: $+81-774-38-3478$

Fax number: +81-774-38-3479

E-mail address: k-yabuuchi@iae.kyoto-u.ac.jp 


\section{Abstract}

Ion irradiations with $6.4 \mathrm{MeV} \mathrm{Fe}^{3+}$ were performed on pure-Fe, $\mathrm{Fe}-1 \mathrm{at} . \% \mathrm{Cr}$, Fe-1at.\%Mn, and $\mathrm{Fe}-1$ at.\%Ni to a nominal damage of $1 \mathrm{dpa}$, at a damage rate of $1 \times 10^{-4}$ $\mathrm{dpa} / \mathrm{s}$, at irradiation temperatures of 473,563 , and $673 \mathrm{~K}$. After irradiations at 473 and $563 \mathrm{~K}, \mathrm{Fe}-1 \mathrm{Mn}$ and $\mathrm{Fe}-1 \mathrm{Ni}$ showed significant irradiation hardening, which was due to irradiation induced dislocation loops in high density. In pure-Fe, the dislocation loops were localized in the vicinity of dislocations, while those in Fe alloys were distributed rather homogeneously. This can be interpreted in terms of the interaction between alloying element and dislocation strain field. Irradiation at $673 \mathrm{~K}$ resulted in the formation of voids in pure-Fe, Fe-1Cr, and $\mathrm{Fe}-1 \mathrm{Mn}$. We found that chromium suppressed void swelling.

\section{Keywords}

Ion irradiation, TEM, Irradiation hardening, Microstructure, Fe binary alloy 


\section{Introduction}

Neutron irradiation induces displacement cascades that lead to the formation of a number of interstitials and vacancies. Most of the interstitials and vacancies recombine with each other, and a relatively small amount of point defects survive. Because both types of point defects created by cascade are thermally unstable, they tend to migrate through the lattice to settle at more stable sites. When identical point defects encounter each other, they invariably form an embryo of defect clusters. Understanding the diffusion mechanisms of point defects that lead to the formation of these clusters is essential to understanding radiation damage mechanisms in materials. The migration of these point defects is affected by the alloying element. Hence, interactions of point defects with solute atoms play key roles in the evolution of the microstructure during irradiation. However, because of the difficulty in directly determining the interaction force or binding energy by experiments, there have been only a few studies of the interactions between point defects and solute atoms [1 - 3]. Consequently, an ab-initio calculation method has been used to estimate the binding energy between a point defect and a solute atom [4-7]. For Fe alloys, it was revealed by Olsson et al. [7] that the interaction between a transition-metal atom and a point defect in body-centered cubic (BCC) Fe was mostly governed by the strain relief due to the size factor in the $4 \mathrm{~d}$ and $5 \mathrm{~d}$ rows, where vacancies are attracted and interstitials are repulsed. On the other hand, the interaction between a point defect and a $3 \mathrm{~d}$ transition-metal solute atom could not be described only by the size factor, which is likely due to antiferromagnetic coupling. Furthermore, it is generally difficult to conclude about the damage accumulation and recombination aspect by means of only ab-initio calculation method. Long time 
simulations, such as molecular-dynamics simulations or kinetic Monte Carlo simulations, are also required. Of course, an experimental study must inevitability be conducted to confirm the simulation results.

Fundamental aspects of radiation damage mechanisms can often be better understood by investigating pure materials and simple model alloys. Furthermore, self-ion (Fe ion) irradiation techniques are useful to investigate irradiation effects in ferritic alloys at various well-controlled conditions such as irradiation temperature, irradiation dose, and damage rate [8 - 10]. Yao and Jenkins $[11,12]$ investigated the nature of dislocation loops in $\mathrm{Fe}-\mathrm{Cr}$ alloy, and they clearly showed additional elements affect the nature of dislocation loops. In the present study, effects of alloying elements such as $\mathrm{Cr}, \mathrm{Mn}$, and $\mathrm{Ni}$ on the irradiation hardening and microstructual evolution in BCC Fe were investigated using ion irradiation to understand the effects of solutes on the elemental processes involved in the formation of defect clusters.

\section{Experimental}

Materials used in the present study are pure-Fe (99.99\%) and $\mathrm{Fe}-1 \mathrm{Cr}, \mathrm{Fe}-1 \mathrm{Mn}$, and $\mathrm{Fe}-1 \mathrm{Ni}$, containing about 1 at. \% of alloying element. The chemical compositions are shown in Table 1. Alloy button ingots were produced by arc-melting in Ar gas using a copper hearth. The alloy buttons were first homogenized at $1273 \mathrm{~K}$ for $24 \mathrm{~h}$ and then at $1098 \mathrm{~K}$ for $48 \mathrm{~h}$, after which they were furnace cooled. The buttons were then cold rolled into $0.3-\mathrm{mm}$-thick sheets without annealing. Disk-shaped specimens with a diameter of $3 \mathrm{~mm}$ were punched from the sheets. All specimens were finally recrystallized at $1098 \mathrm{~K}$ for $0.5 \mathrm{~h}$, followed by quenching in iced water. 
These materials were irradiated using a dual beam irradiation experimental test facility (DuET) at Kyoto University. Irradiation with $6.4 \mathrm{MeV} \mathrm{Fe}{ }^{3+}$ ions was performed to a nominal displacement damage of $1 \mathrm{dpa}$ at a nominal rate of $1 \times 10^{-4} \mathrm{dpa} / \mathrm{s}$. A typical depth profile of the displacement damage calculated by the SRIM code is shown in Fig. 1 [13]. The nominal dpa is defined as a displacement damage at a depth of $600 \mathrm{~nm}$ from the irradiated surface. The area near the surface strongly has the effect of surface sink, and the damage peak region has a large dpa gradient. That is why these areas were not appropriate to evaluate the radiation effect, and a depth of $600 \mathrm{~nm}$ is selected for the nominal dpa. The irradiation temperature was measured by thermography and was controlled at 473,563 , and $673 \mathrm{~K}$ within $\pm 10 \mathrm{~K}$.

To investigate the irradiation hardening, a nanoindentation test was adopted using Agilent Technologies Inc. Model Nano Indenter G200 with a Berkovich type indentation tip. The indentation was performed on the irradiation surface in the direction parallel to $\mathrm{Fe}^{3+}$ beam incident direction. The constant stiffness measurement (CSM) technique was used to obtain the depth profile of hardness. A depth dependence of Fe-1.4Mn alloy irradiated to $1 \mathrm{dpa}$ at $563 \mathrm{~K}$ is shown in Fig. 2. An indentation size effect (ISE) [14] was observed, and the obtained hardness decreased as the indentation depth increased. In an irradiated specimen, the hardness rapidly decreased over an indentation depth of $300 \mathrm{~nm}$, where the strain range exceeds the irradiation damage peak and the obtained hardness reflects the hardness of the unirradiated region. Therefore, both the irradiated $\left(H_{\text {irr. }}\right)$ and unirradiated hardness $\left(H_{\text {unirr. }}\right)$ are defined as the hardness at an indentation depth of $250 \mathrm{~nm}$ in the present study. As shown in Fig. 2, which was the depth dependence of hardness in irradiated $\mathrm{Fe}-1.4 \mathrm{Mn}$ alloy, the hardness of the indentation depth of $250 \mathrm{~nm}$ includes the irradiation effect. Irradiation hardening $\Delta H$ is defined as 
the difference in the hardness between before and after irradiation; $\Delta H=H_{\text {irr. }}-H_{\text {unirr. }}$.

Microstructure observations were carried out by transmission electron microscopy (TEM) at an acceleration voltage of $200 \mathrm{kV}$. Thin foils for TEM observations were prepared using a focused ion beam (FIB) system, and they were cross-sectional specimens. The foils were finished using an ultralow-energy Ar ion beam sputtering system (Technorg-Linda GentleMill) or electropolishing for $10 \mathrm{~ms}$ to remove the surface damage layer induced by FIB processing. The damage layers induced by FIB are able to be removed by GentleMill, but some artifacts induced by GentleMill remain [15]. In this study, as shown in Fig. 3, black dots remained after the GentleMill process, and they were artifacts induced by GentleMill. That is because the black dots were observed in the unirradiated area beneath the peak-damaged area and the contrast of artifacts was clearly different from that of loops. The foil thickness was measured by convergent beam electron diffraction (CBED) method.

Microstructure observations were made at the region about $600 \mathrm{~nm}$ from the irradiated surface in the cross-sectional specimens. The number density of dislocation loops was measured by the following equations based on $\boldsymbol{g} \cdot \boldsymbol{b}$ contrast and the measurement is based on the assumption that only $1 / 2<111>$ and $<100>$ loops exist.

$$
\begin{array}{ll}
d_{111}+1 / 3 d_{100}=A & \text { for } \boldsymbol{g}=200 \\
1 / 2 d_{111}+2 / 3 d_{100}=B & \text { for } \boldsymbol{g}=110
\end{array}
$$

where $d_{111}$ and $d_{100}$ are the number density of $1 / 2<111>$ loops and $<100>$ loops, respectively. $A$ is the number density of loops visible in the micrograph with $g=<200>$, and $B$ is the number density of loops visible in the micrograph with $g=<110>$. In the micrograph with $g=<200>$, all of the $1 / 2<111>$ loops are visible and only one-third of the $<100>$ loops are visible. In the same way, in the micrograph with $g=<110>$, half of the 
$1 / 2<111>$ loops are visible, and only two-thirds of the $<100>$ loops are visible. Therefore the total number density, $d_{\text {total }}$ is expressed by the following equations.

$$
\begin{aligned}
& d_{111}=2 / 3(2 A-B) \\
& d_{100}=2 B-A \\
& d_{\text {total }}=d_{111}+d_{100}=1 / 3(A+4 B)
\end{aligned}
$$

\section{Results and discussion}

Irradiation hardening of pure-Fe, $\mathrm{Fe}-1 \mathrm{Cr}, \mathrm{Fe}-1 \mathrm{Mn}$, and $\mathrm{Fe}-1 \mathrm{Ni}$ irradiated to $1 \mathrm{dpa}$ are shown as a function of irradiation temperature in Fig. 4. At 473 and $563 \mathrm{~K}$, irradiation hardening of $\mathrm{Fe}-1 \mathrm{Mn}$ and $\mathrm{Fe}-1 \mathrm{Ni}$ was enhanced significantly compared to that of pure-Fe. At $673 \mathrm{~K}$, on the other hand, pure-Fe and Fe-1Mn showed almost no irradiation hardening, while $\mathrm{Fe}-1 \mathrm{Cr}$ and $\mathrm{Fe}-1 \mathrm{Ni}$ showed irradiation hardening. Irradiation hardening of pure-Fe, $\mathrm{Fe}-1 \mathrm{Mn}$, and $\mathrm{Fe}-1 \mathrm{Ni}$ decreased as the irradiation temperature increased. Irradiation hardening of $\mathrm{Fe}-1 \mathrm{Cr}$ did not show a temperature dependence.

Fig. 5 shows TEM micrographs of pure-Fe, Fe-1Cr, Fe-1Mn, and Fe-1Ni irradiated to 1 dpa at 563 K. Figs. 5 (a) and (b) are bright and dark field images for pure-Fe, Figs. 5 (c) and (d) are for Fe-1Cr, Figs. 5 (e) and (f) are for Fe-1Mn, and Figs. 5 (g) and (h) are for Fe-1Ni. As shown in Figs. 5 (a) and (b), relatively a high number density of dislocation loops was observed at the vicinity of dislocations in irradiated pure-Fe. Dislocations decorated with dislocation loops and rafts of dislocation loops were distributed in the irradiated region, and there were a few isolated dislocation loops, indicating inhomogeneous formation of the loops in the matrix. On the other hand, 
isolated dislocation loops formed homogeneously in high density in the irradiated $\mathrm{Fe}^{-1} \mathrm{Mn}$ and $\mathrm{Fe}-1 \mathrm{Ni}$. For $\mathrm{Fe}-1 \mathrm{Mn}$, it has been documented that irradiation hardening is enhanced significantly because of high density dislocation loops [16, 17]. For Fe-1Ni, the effect of $\mathrm{Ni}$ addition on irradiation embrittlement and microstructural evolution was studied in research on the Ni-isotope tailoring (NIT) method on the analogy of $\mathrm{He}$ implantation $[18,19]$. It was reported that $\mathrm{Ni}$ in itself affects irradiation hardening and microstructural evolution in $\mathrm{Ni}$ added to steel [20], which is supported by the results of the present study.

Rafts of dislocation loops and dislocation decoration by dislocation loops were observed in only pure-Fe. The formation of these localized distributions of dislocation loops has been considered to be due to the interaction between gliding dislocation loops and the strain field of dislocations [21]. That is, the gliding dislocation loops induced by irradiation can be trapped at the vicinity of a dislocation because of the presence of the strain field. The dislocation loops may gradually climb to and be absorbed by the dislocation. When the trapping or arriving rate of dislocation loops at dislocations is higher than the absorption rate, the dislocation loops remain in the vicinity of the dislocations, which results in the formation of the rafts and dislocation decoration. Effects of alloying elements can be interpreted in terms of two mechanisms. In one mechanism, alloying element atoms segregate at dislocations and attenuate the strain field of dislocations. In the other mechanism, the alloying element atoms trap dislocation loops and decrease the arrival rate of loops at dislocations. In fact, the mobility of dislocation loops in Fe-Mn alloy was reduced by $\mathrm{Mn}$ addition in $\mathrm{BCC} \mathrm{Fe}$, which will be discussed in more detail elsewhere [22].

Fig. 6 shows TEM micrographs of pure-Fe, Fe-1Cr,Fe-1Mn, and $\mathrm{Fe}-1 \mathrm{Ni}$ irradiated 
to $1 \mathrm{dpa}$ at $673 \mathrm{~K}$. No dislocation loops were observed in irradiated pure-Fe. Although many black dots were observed, they were not dislocation loops but were artifacts induced by the GentleMill. It is possible that dislocation loops grew too large to be observed in the thin film by TEM. In $\mathrm{Fe}-\mathrm{Cr}$ and $\mathrm{Fe}-\mathrm{Mn}$ alloys, large dislocation loops were observed in low densities with small black dots of artifacts induced by GentleMill.

Table 2 summarizes number densities and average sizes of dislocation loops in the irradiated pure-Fe and Fe binary alloys that were described above. The relationship between the yield stress and the microstructure is often described using Orowan type equations. In the equation, the yield stress is a function of $(N d)^{1 / 2}$. Comparing Fig. 4 to Table 2, the irradiation hardening was likely due to dislocation loops, although the hardness was not precisely evaluated because of the ISE. And it is possible that solute segregation or fine precipitation exist in part. However, dislocation loops were responsible for most of the observed irradiation hardening.

On the other hand, voids were observed in all the irradiated alloys to $1 \mathrm{dpa}$ at $673 \mathrm{~K}$, as shown in Fig. 7. The number densities and average diameters of voids in all the materials are summarized in Table 3 . The results indicate that vacancies were trapped by $\mathrm{Cr}$, and the number density of voids were high. Little et al. showed that the swelling peak temperatures of pure-Fe and $\mathrm{Fe}-\mathrm{Cr}$ binary alloys irradiated to 30 dpa by neutron were in the range from 653 to $733 \mathrm{~K}$ [23]. This study using ion irradiation agrees with the results of the neutron irradiation experiment; voids were not observed in pure-Fe and Fe binary alloys irradiated at $563 \mathrm{~K}$, but were observed in alloys irradiated at $673 \mathrm{~K}$. It should be noted that $\mathrm{Cr}$ addition suppressed the swelling. Little et al. proposed that the suppressing effect of $\mathrm{Cr}$ on void swelling in iron alloys and steels could be understood in terms of the trapping of vacancies by $\mathrm{Cr}$, although the binding energy 
between $\mathrm{Cr}$ and the vacancy was low [24]. On the other hand, Lam et al. suggested that the weak trapping of vacancies by $\mathrm{Cr}$ would lead to enhanced recombination [25]. The mechanisms of void swelling resistance resulting from $\mathrm{Cr}$ addition have not been cleared yet, but it is believed that $\mathrm{Cr}$ affects the behavior of vacancies and their clusters in $\mathrm{BCC}$ Fe. Gelles reported that the highest swelling rate is $0.097 \% / \mathrm{dpa}$ for $\mathrm{Fe}-9 \mathrm{Cr}$ irradiated by neutrons at $693 \mathrm{~K}$, and the swelling rate of $\mathrm{Fe}-3 \mathrm{Cr}$ is $0.006 \% / \mathrm{dpa}$ [26]. In this study, the swelling rate of $\mathrm{Fe}-1 \mathrm{Cr}$ is estimated to be $0.003 \% / \mathrm{dpa}$ in the present dose range.

\section{Summary}

The effects of alloying elements $\mathrm{Cr}, \mathrm{Mn}$, and $\mathrm{Ni}$ on irradiation hardening and microstructual evolution in BCC Fe were investigated using ion irradiation and the following results were obtained.

1. At irradiation temperature of 473 and $563 \mathrm{~K}$, the irradiation hardening of $\mathrm{Fe}^{-1}$ at.\% $\mathrm{Mn}$ and $\mathrm{Fe}-1$ at.\% $\mathrm{Ni}$ alloy are enhanced significantly compared to that of pure-Fe.

2. The significant irradiation hardening of $\mathrm{Fe}^{-1}$ at.\% $\mathrm{Mn}$ and $\mathrm{Fe}-1$ at.\% $\mathrm{Ni}$ alloy resulted from the formation of dislocation loops in high densities.

3. In pure-Fe, the dislocation loops were localized at the vicinity of dislocations, while those in Fe alloys were distributed rather homogeneously. This can be interpreted in terms of the interaction between the alloying element and the dislocation strain field.

4. At the irradiation temperature of $673 \mathrm{~K}$, voids were observed in pure-Fe, $\mathrm{Fe}-1$ 
at.\% $\mathrm{Cr}$, and $\mathrm{Fe}-1$ at.\% $\mathrm{Mn}$ alloy. Chromium suppressed void swelling. 


\section{Acknowledgements}

This work is supported by the Japan Society for the Promotion of Science (JSPS). 


\section{References}

1. F. Maury, A. Lucasson, P. Lucasson, Y. Loreaux, P. Moser, J. Phys. F 16 (1986) 523.

2. F. Maury, A. Lucasson, P. Lucasson, P. Moser, F. Faudot, J. Phys. Condens. Matter $2(1990) 9291$.

3. H. Abe, E. Kuramoto, J. Nucl. Mater. 271 (1999) 209.

4. R. Ngyam-Happy, P. Olsson, C.S. Becquart, C. Domain, J. Nucl. Mater. 407 (2010) 16.

5. Toshiharu Ohnuma, Naoki Soneda, Misako Iwasawa, Acta Materialia 57 (2009) 5947.

6. Shenyan Huang, Daniel L. Worthington, Mark Asta, Vidvuds Ozolins, Gautam Ghosh, Peter K. Liaw, Acta Materialia 58 (2010) 1982.

7. P. Olsson, T.P.C. Klaver, C. Domain, Phys. Rev. B 81 (2010) 054102.

8. K. Yutani, R. Kasada, H. Kishimoto, A. Kimura. J. ASTM Int. 4 (2007).

9. M. Ando, E. Wakai, T. Sawai, H. Tanigawa, K. Furuya, S. Jitsukawa, H. Takeuchi, K. Oka, S. Ohnuki, A. Kohyama, J. Nucl. Mater. 329-333 (2004) 1137.

10. H. Ogiwara, A. Kohyama, H. Tanigawa, H. Sakasegawa, Fusion Eng. Des. 81 (2006) 1091.

11. Z. Yao, Hernández-Mayoral, M.L. Jenkins, and M.A. Kirk, Philosophical Magazine, 88 (2008) 2851.

12. M.L. Jenkins, Z. Yao, M. Hernández-Mayoral, and M.A. Kirk, J. Nucl. Mater. 389 (2009) 197.

13. SRIM code, http://www.srim.org

14. G.M. Pharr, E.G. Herbert, Y. Gao, Annu. Rev. Mater. Res. 40 (2010) 271. 
15. Hyun-Ha Jin, Chansun Shin, and Junhyun Kwon, Journal of Electron Microscopy 59(6) (2010) 463-468.

16. Kiyohiro Yabuuchi, Masashi Saito, Ryuta Kasada, and Akihiko Kimura, J. Nucl. Mater. 414 (2011) 498.

17. Kiyohiro Yabuuchi, Hiroki Yano, Ryuta Kasada, Hirotatsu Kishimoto, and Akihiko Kimura, J. Nucl. Mater. 417 (2011) 988.

18. D.S. Gelles, J. Nucl. Mater. 230 (1996) 187.

19. R.L. Klueh, D.J. Alexander, J. Nucl. Mater. 230 (1996) 191.

20. R. Kasada, A. Kimura, Mater. Trans. 46 (2005) 475.

21. H. Trinkaus, B.N. Singh, and A.J.E. Foreman, J. Nucl. Mater. 249 (1997) 91.

22. K. Yabuuchi, R. Kasada, and A. Kimura, to be submitted.

23. E.A. Little and D.A. Stow, J. Nucl. Mater. 87 (1979) 25.

24. E.A. Little and D.A. Stow, Met. Sci. 14 (1980) 89.

25. N.Q. Lam, P.R. Okamoto, and H. Wiedersich, J. Nucl. Mater. 74 (1978) 101.

26. D.S. Gelles J. Nucl. Mater. 225 (1995) 163. 


\section{Tables}

Table 1 Chemical compositions of pure-Fe, $\mathrm{Fe}-1 \mathrm{Cr}, \mathrm{Fe}-1 \mathrm{Mn}$, and $\mathrm{Fe}-1 \mathrm{Ni}$ alloys.

\begin{tabular}{cccccccc}
\hline Material & $\mathrm{C}$ & $\mathrm{O}$ & $\mathrm{N}$ & $\mathrm{Cr}$ & $\mathrm{Mn}$ & $\mathrm{Ni}$ & $\mathrm{Fe}$ \\
& & $($ wt. ppm) & & & & (at. \%) & \\
\hline pure-Fe & 2 & 550 & 70 & - & - & - & bal. \\
$\mathrm{Fe}-1 \mathrm{Cr}$ & 2 & 580 & 7 & 0.92 & - & - & bal. \\
$\mathrm{Fe}-1 \mathrm{Mn}$ & 2 & 600 & 7 & - & 0.86 & - & bal. \\
$\mathrm{Fe}-1 \mathrm{Ni}$ & 2 & 480 & 6 & - & - & 0.94 & bal. \\
\hline
\end{tabular}


Table 2 Number densities and average diameters of dislocation loops in pure-Fe and $\mathrm{Fe}$ based binary alloys.

\begin{tabular}{|c|c|c|}
\hline & $563 \mathrm{~K}$ & $673 \mathrm{~K}$ \\
\hline & Ave. diameter (nm) & Ave. diameter (nm) \\
\hline & Number density $\left(\mathrm{m}^{-3}\right)$ & Number density $\left(\mathrm{m}^{-3}\right)$ \\
\hline \multirow{3}{*}{ Pure-Fe } & Rafts and & \\
\hline & & No loop \\
\hline & dislocation decoration & \\
\hline \multirow{3}{*}{$\mathrm{Fe}-1 \mathrm{Cr}$} & 24.0 & 73.2 \\
\hline & & \\
\hline & $7.5 \times 10^{20}$ & $1.1 \times 10^{21}$ \\
\hline \multirow{3}{*}{$\mathrm{Fe}-1 \mathrm{Mn}$} & 23.6 & 111 \\
\hline & & \\
\hline & $4.3 \times 10^{21}$ & $1.7 \times 10^{20}$ \\
\hline \multirow{3}{*}{$\mathrm{Fe}-1 \mathrm{Ni}$} & 4.1 & 33.6 \\
\hline & & \\
\hline & $3.5 \times 10^{22}$ & $3.4 \times 10^{21}$ \\
\hline
\end{tabular}


Table 3 Void densities and average diameters in pure-Fe and Fe based binary alloys irradiated to $1 \mathrm{dpa}$ at $673 \mathrm{~K}$.

\begin{tabular}{ccccc}
\hline & Pure-Fe & Fe-1Cr & Fe-1Mn & Fe-1Ni \\
\hline \hline Ave. diameter (nm) & 19 & 3.5 & 11 & 14 \\
Number density (m-3) & $1.4 \times 10^{20}$ & $1.3 \times 10^{21}$ & $5.8 \times 10^{20}$ & $1.3 \times 10^{21}$ \\
Swelling (\%) & 0.05 & 0.003 & 0.04 & 0.17 \\
\hline
\end{tabular}




\section{Figures}

Fig. 1 Depth profile of the displacement damage (dpa) of $6.4 \mathrm{MeV} \mathrm{Fe}^{3+}$ ion irradiation.

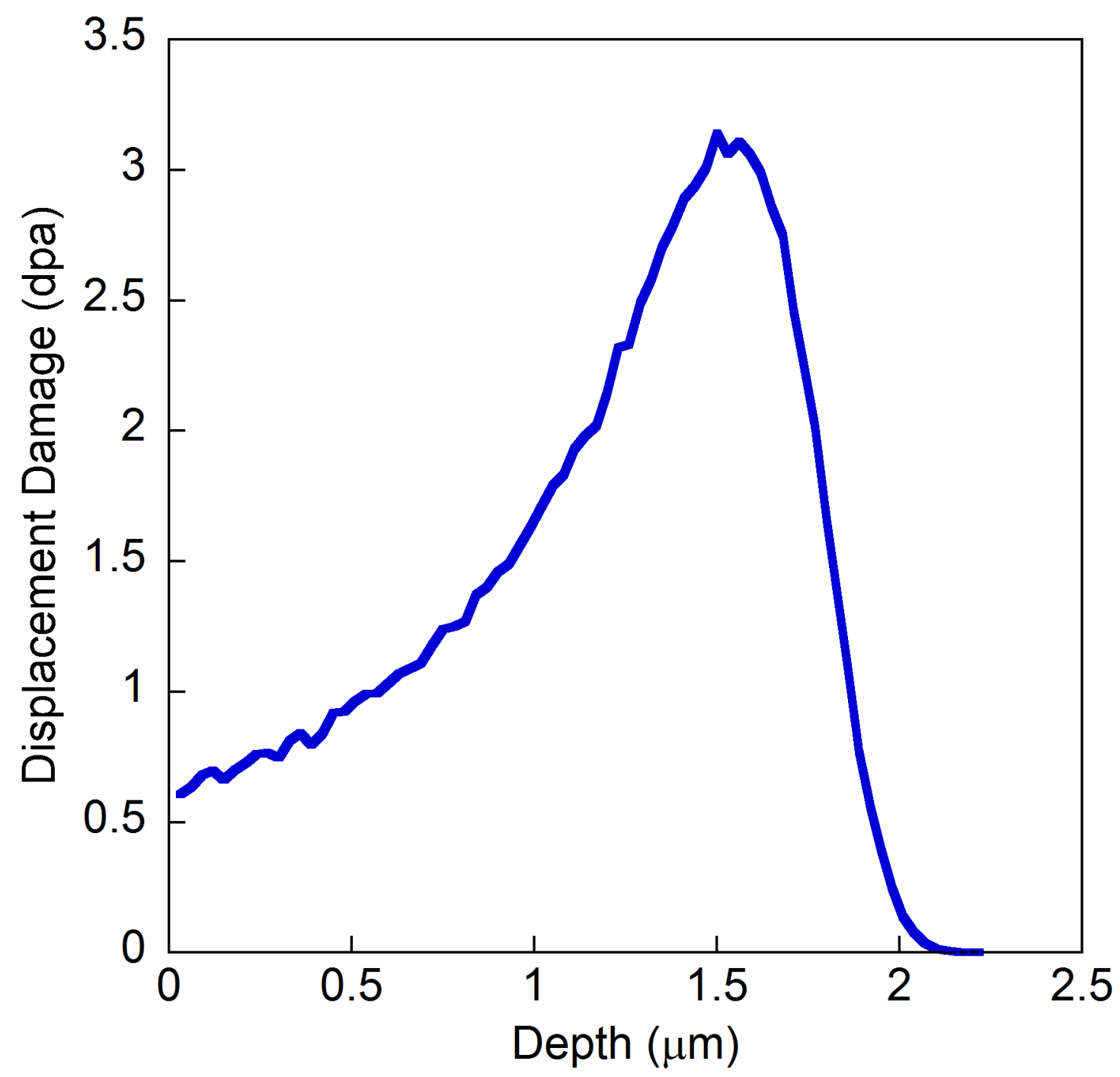


Fig. 2 Depth profiles of the hardness of unirradiated and irradiated Fe-1.4Mn alloy.

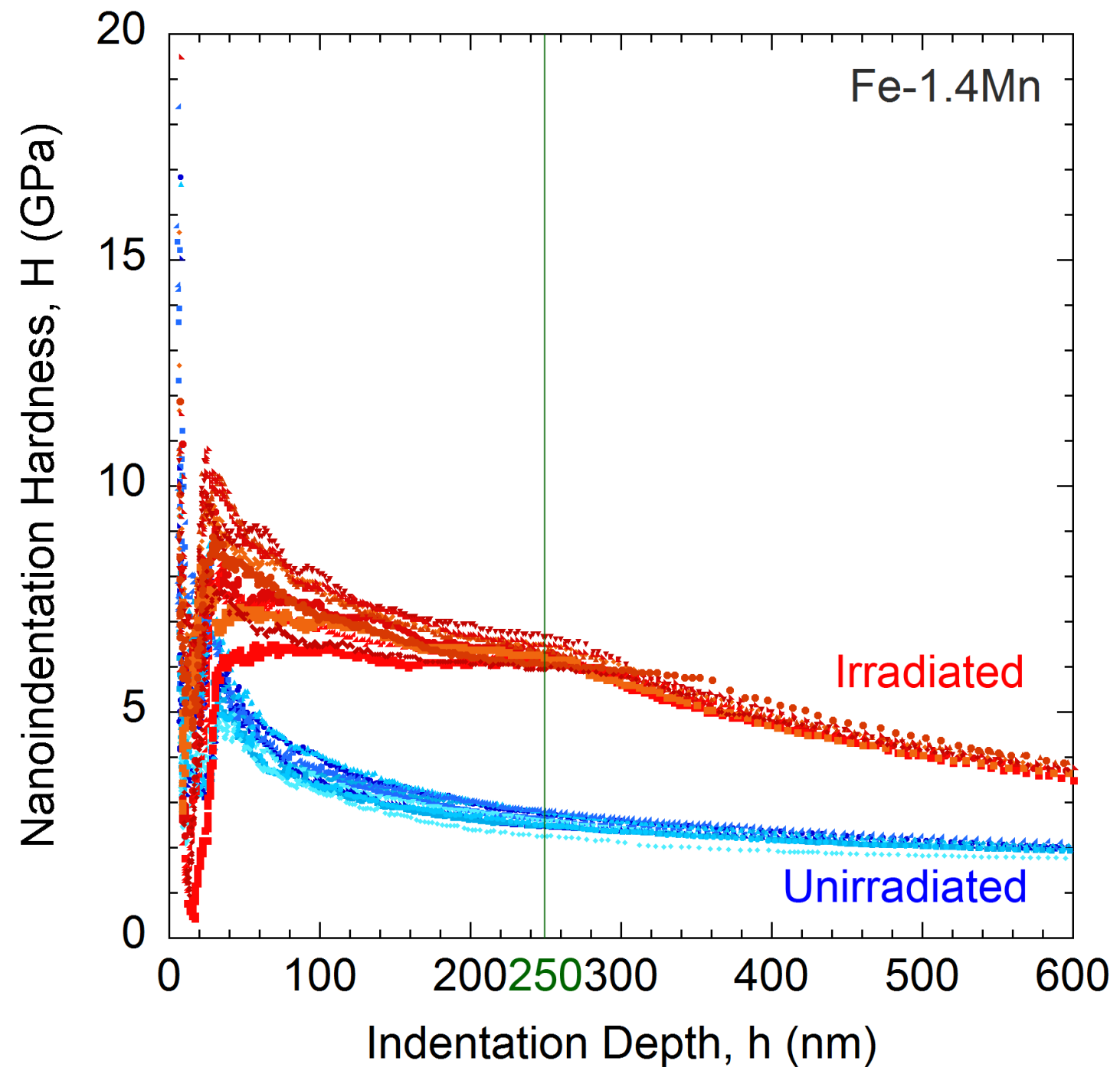


Fig. 3 Artifacts induced by GentleMill process in an irradiated pure-Fe; (a) bright field image and (b) dark field image using $\boldsymbol{g}=110$ close to [1 111$]$.

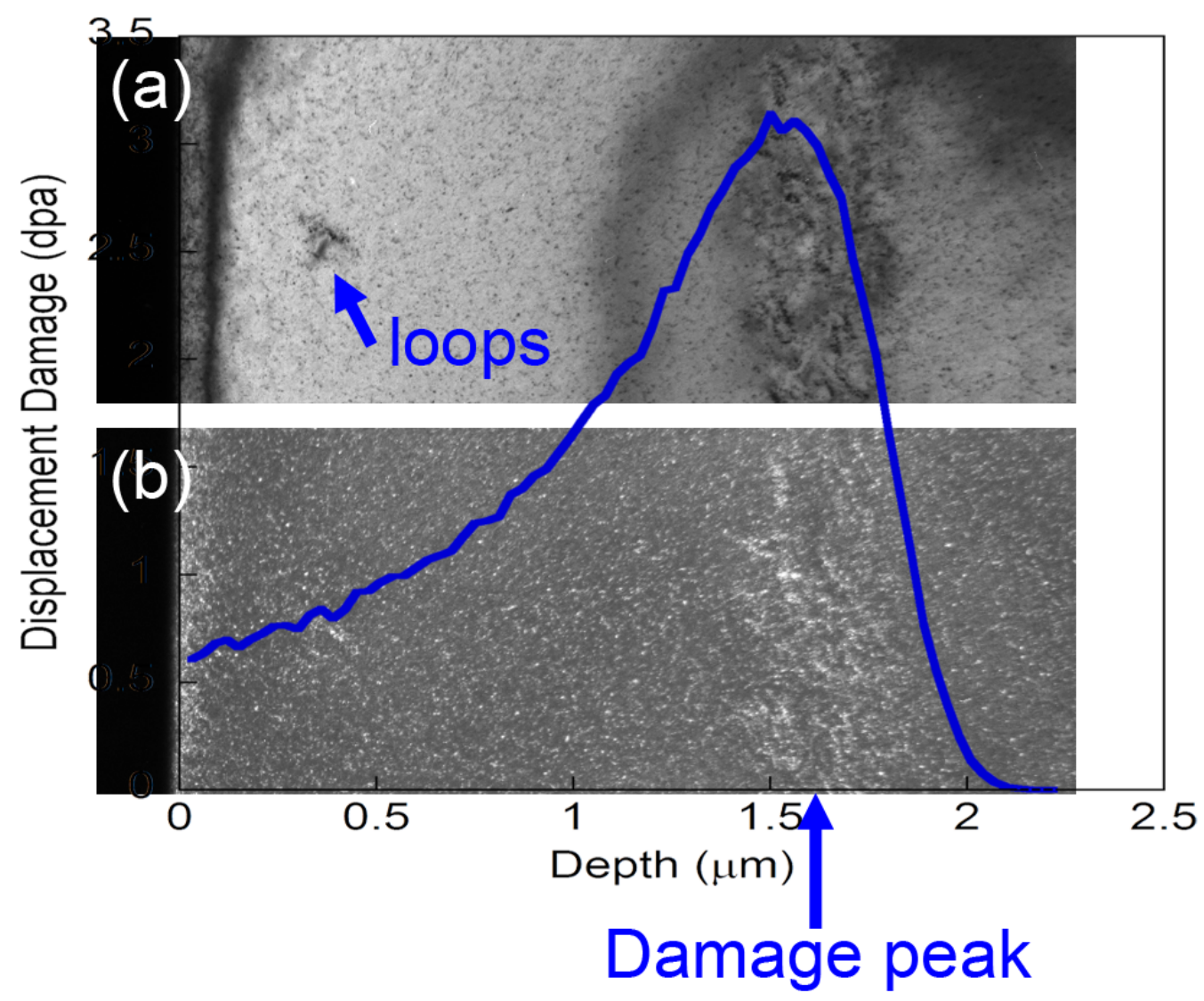


Fig. 4 Irradiation hardening behaviors of pure-Fe, Fe-1Cr, Fe-1Mn, and $\mathrm{Fe}-1 \mathrm{Ni}$ irradiated to $1 \mathrm{dpa}$ as a function of irradiation temperature.

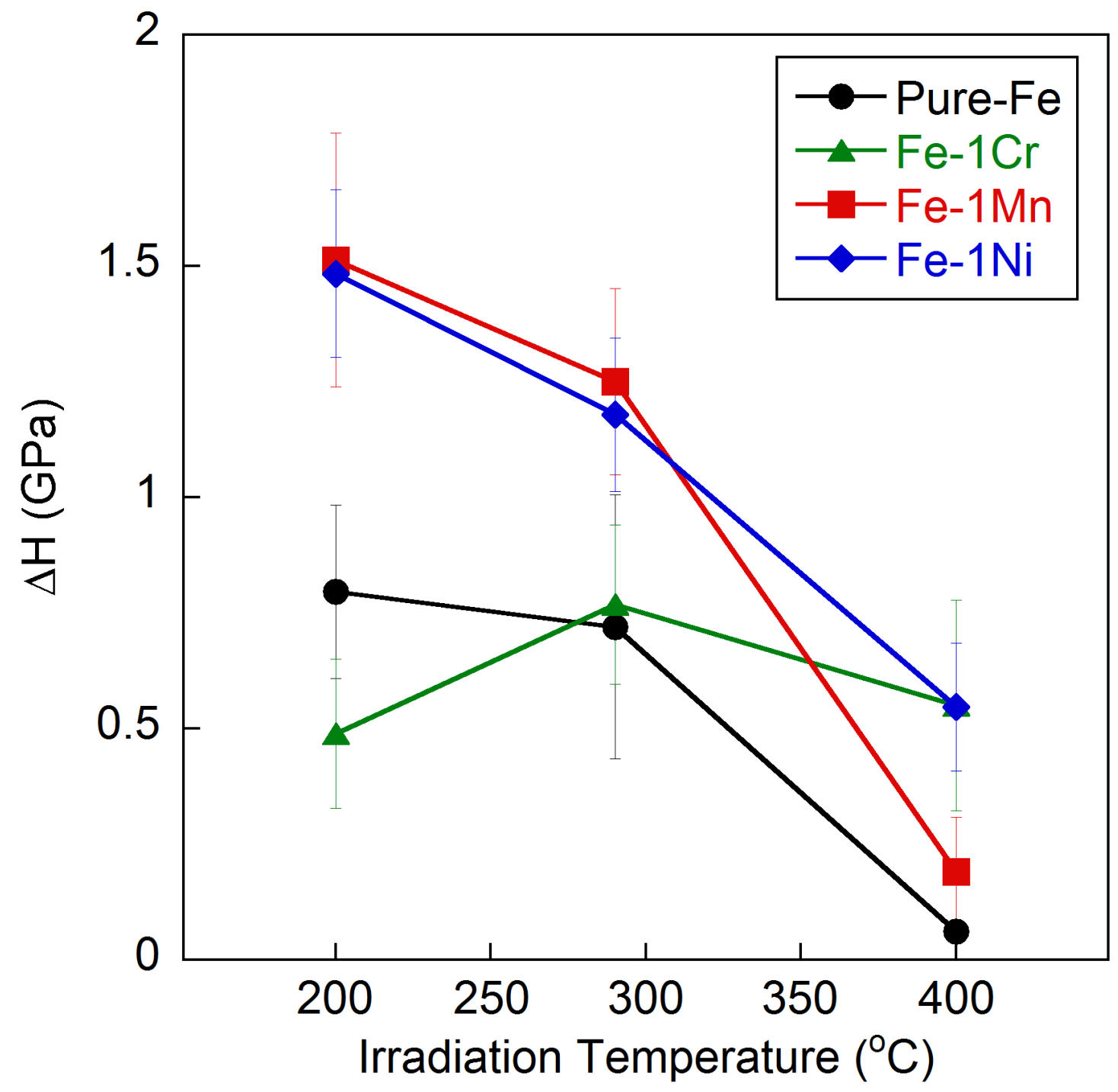


Fig. 5 Bright and dark field images of pure-Fe, Fe-1Mn, and Fe-1Ni irradiated to 1 dpa at $290{ }^{\circ} \mathrm{C}$ : (a, b) pure-Fe using $g=01 \overline{1}$ close to [011] pole, (c, d) $\mathrm{Fe}-1 \mathrm{Cr}$ using $\boldsymbol{g}=110$ close to [001] pole, (e, f) Fe-1Mn using $\boldsymbol{g}=110$ close to [001] pole, and $(\mathrm{g}, \mathrm{h}) \mathrm{Fe}-1 \mathrm{Ni}$ using $\boldsymbol{g}=110$ close to [1]11].
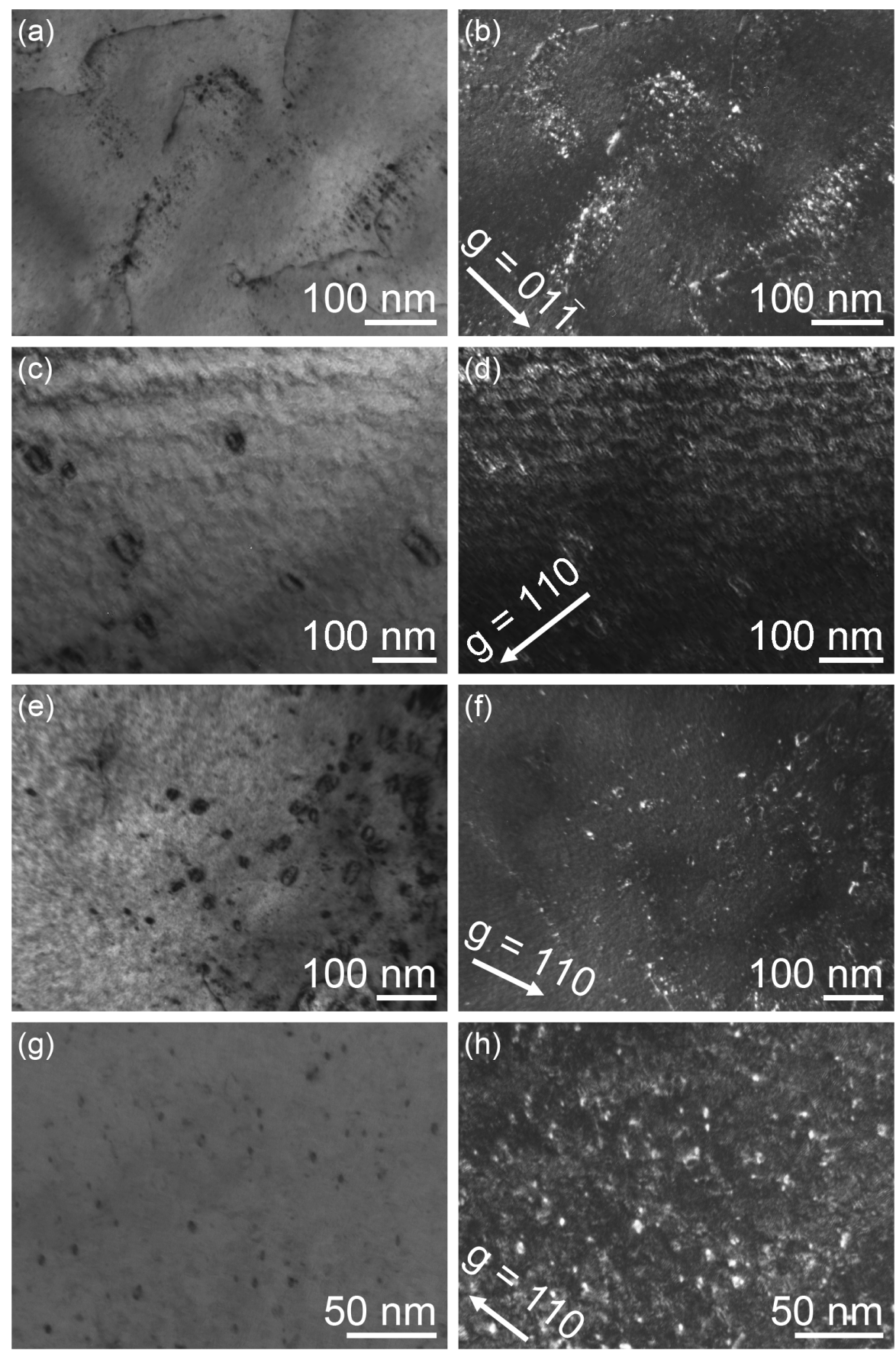
Fig. 6 Bright and dark field images of pure-Fe, Fe-1Cr, and Fe-1Mn irradiated to 1 dpa at $400{ }^{\circ} \mathrm{C}$ : (a, b) pure-Fe using $g=110$ close to [001] pole, (c, d) $\mathrm{Fe}-1 \mathrm{Cr}$ using $\boldsymbol{g}=110$ close to [111] pole, (e, f) Fe-1Mn using $\boldsymbol{g}=01 \overline{1}$ close to [011] pole, and $(\mathrm{g}, \mathrm{h}) \mathrm{Fe}-1 \mathrm{Ni}$ using $\boldsymbol{g}=200$ close to [001] pole.
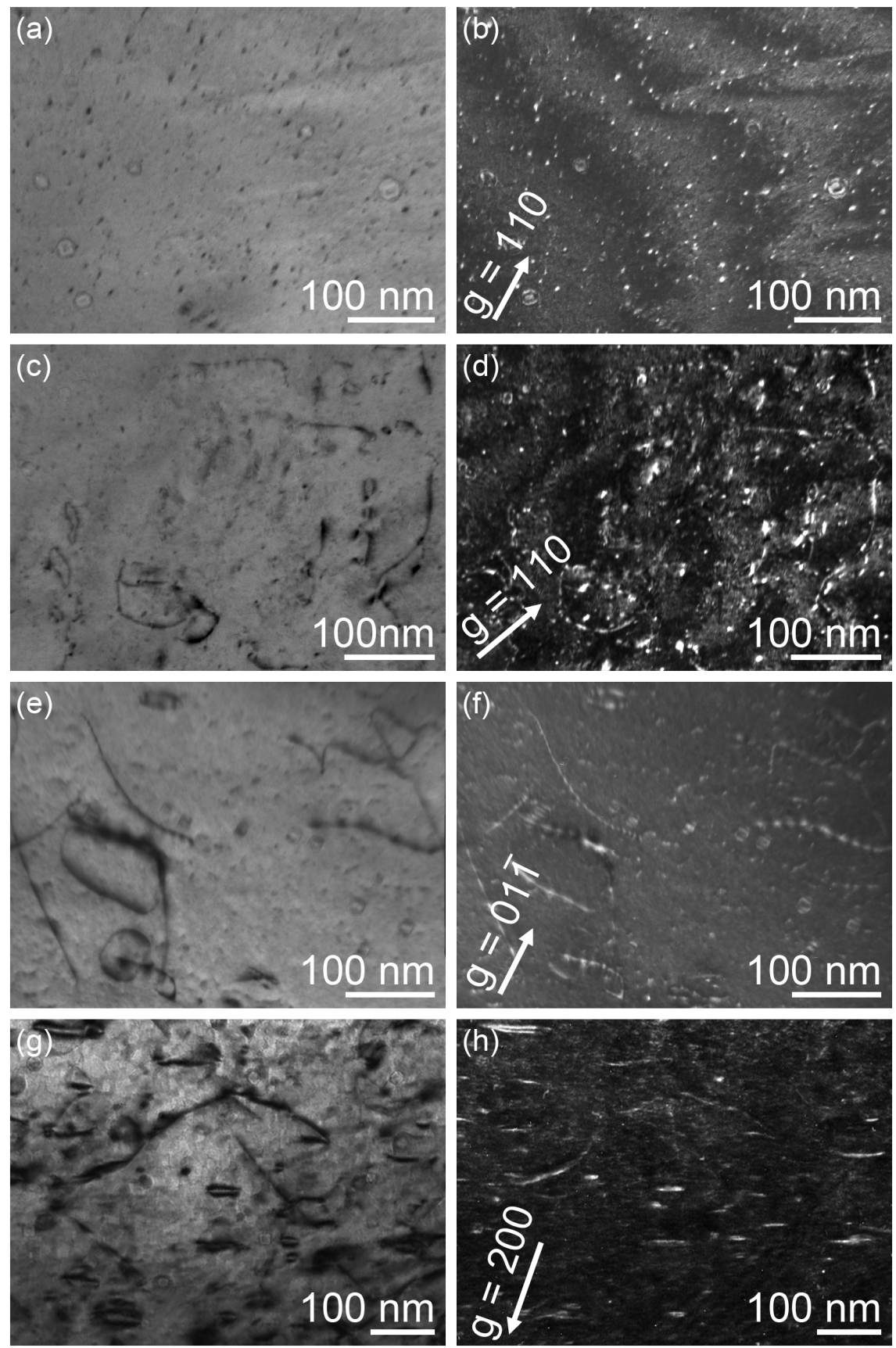
Fig. 7 TEM micrographs observed in a defocus condition: (a) pure-Fe, (b) Fe-1Cr, (c) $\mathrm{Fe}-1 \mathrm{Mn}$, and (d) Fe-1Ni irradiated to 1 dpa at $400{ }^{\circ} \mathrm{C}$.
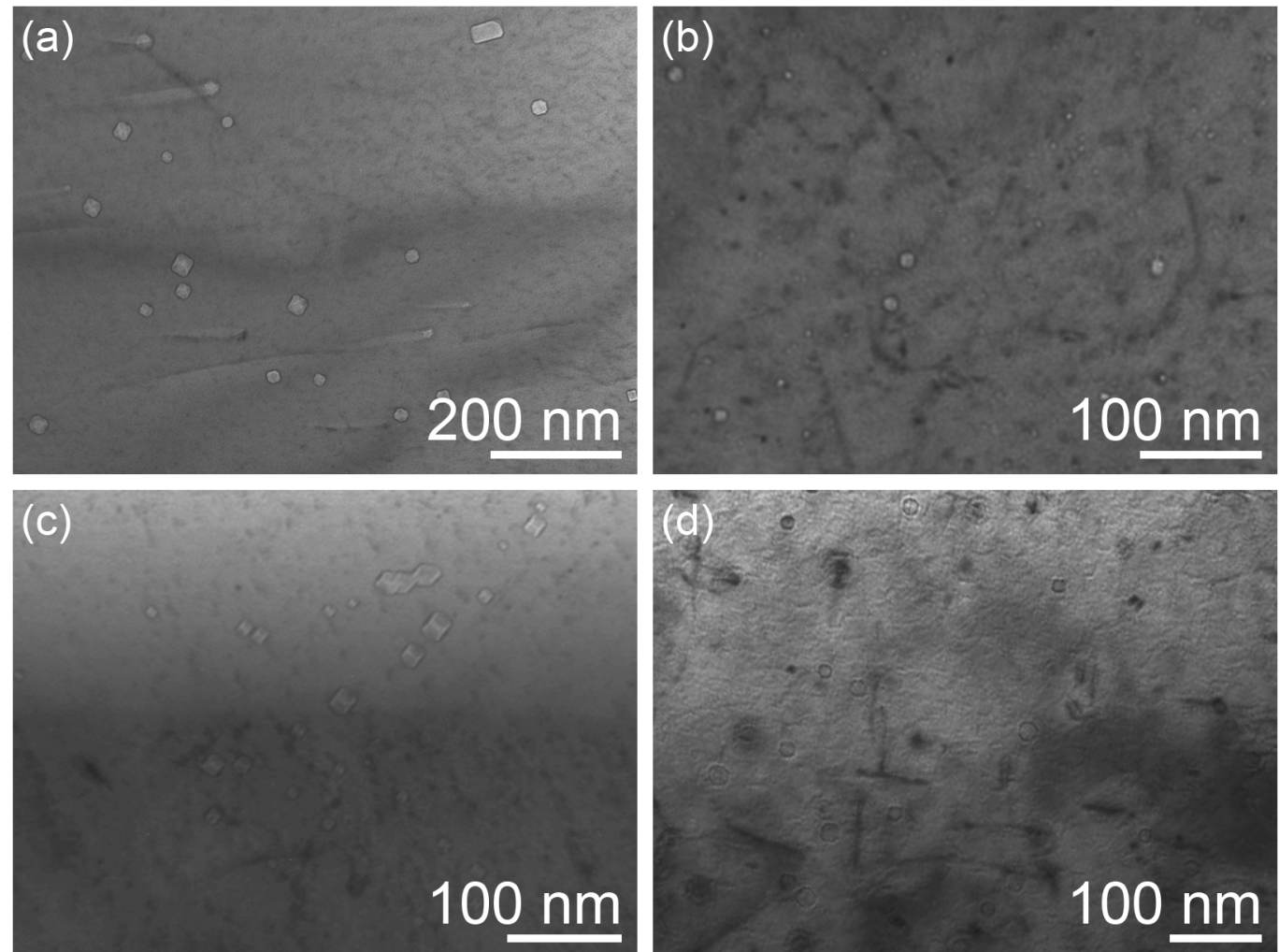